\title{
Hemodynamic Effects of Cecal Ligation Sepsis in Dogs ${ }^{1}$
}

\author{
Jack L. Cronenwett, M.D., ${ }^{2}$ And S. Martin Lindenauer, M.D. \\ Department of Surgery, University of Michigan and Vascular Research Laboratory, Ann Arbor Veterans \\ Administration Medical Center, Ann Arbor, Michigan 48109
}

Presented at the Annual Meeting of the Association for Academic Surgery, Chicago, Illinois, November 9-11, 1981

\begin{abstract}
Cecal ligation sepsis was studied in eight pentobarbital-anesthetized dogs with hemodynamic measurements at baseline, 2 days after cecal ligation, and following Ringer's lactate resuscitation. Microsphere techniques were used to measure peripheral arteriovenous (A-V) shunting and distribution of cardiac output. Cecal ligation sepsis was manifested by pyrexia, leukocytosis, decreased blood pressure, and purulent peritonitis. Although cardiac index (CI) increased in two, decreased in four, and was unchanged in two dogs, femoral artery blood flow (FAQ) decreased in all animals (125 to $84 \mathrm{ml} / \mathrm{min}, P<0.01$ ). Hindlimb A.V O $\mathrm{O}_{2}$ difference increased while $\mathrm{O}_{2}$ consumption and A-V shunting did not change. Distribution of cardiac output increased significantly to the kidneys $(\uparrow 63 \%, P<0.01)$ and liver $(\uparrow 168 \%, P<0.01)$, but was unchanged to skin, pancreas, and skeletal muscle. Intrarenal distribution of blood flow did not change despite increased total renal blood flow during sepsis. Ringer's lactate resuscitation $\left(20 \mathrm{ml} / \mathrm{kg}\right.$ ) during sepsis increased $\mathrm{CI}$, while FAQ and A-V $\mathrm{O}_{2}$ differences returned to baseline values. Hindlimb A-V shunting remained low and unchanged.

In contrast to the effects of local inflammation in canine septic hindlimbs, there does not appear to be a specific vasodilator released during cecal ligation sepsis which causes increased peripheral blood flow and elevated A-V shunting. Cecal ligation in dogs, however, does not mimic the disproportionately low peripheral resistance and reduced $\mathrm{O}_{2}$ extraction seen in hyperdynamic human sepsis. These results should, therefore, be interpreted with caution.
\end{abstract}

A unique hemodynamic feature of human sepsis is the initially elevated cardiac output with disproportionately reduced peripheral vascular resistance. Although this hyperdynamic state may deteriorate to a low output, depressed circulation, it is distinctly different from other shock states and has attracted considerable investigative attention. While altered intermediary metabolism due to invading bacterial organisms has been strongly implicated as the stimulus for such hyperdynamic circulation, the mechanism for changes in vascular resistance is not established. Earlier studies demonstrated increased venous oxygen saturation despite an increased metabolic demand and evoked the suggestion that at least physiologic arteriovenous $(A-V)$ shunting might exist $[3,8]$.

${ }^{1}$ Funded in part by the Veterans Administration Merit Review Grant.

${ }^{2}$ Dr. Cronenwett is a VA Research Associate. To whom reprint requests should be addressed.
More recent studies suggest that metabolic derangements including increased gluconeogenesis, impaired pyruvate metabolism, and reduced hydrogen ion acceptors are responsible for the elevated venous oxygen and lactate levels observed in sepsis [15]. A contribution to these hemodynamic phenomena by $A-V$ shunting, however, has not been excluded.

The significance of A-V anastomoses (AVAs) in human circulatory physiology has not been determined, although such AVAs have been anatomically documented in the skin and subcutaneous tissue of both animals and man [13]. During certain conditions in animals, AVAs have been shown to accommodate $30-40 \%$ of the hindlimb circulation [5], a feat accomplished by their large cross-sectional arca comparcd to capillary beds [13]. Previous experiments to assess the contribution of such AVAs to the overall septic response have been frustrated 


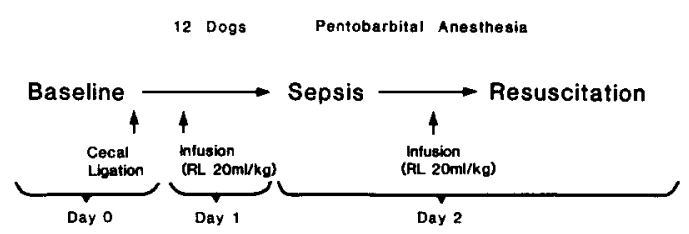

FIG. 1. Protocol for cecal ligation sepsis and resuscitation used in this study.

by indirect measurement of A-V shunting and the necessity for using animal models of sepsis.

Using the canine septic hindlimb model of Hermreck and Thal [10], we previously demonstrated significant $\mathrm{A}-\mathrm{V}$ shunting which was highly correlated with increased total hindlimb blood flow [4]. However, since this model represented local inflammation rather than systemic effects of generalized or remote sepsis, the implications of this study were limited. Other investigators using a canine cecal ligation model for sepsis concluded that significant peripheral A-V shunting does not contribute to the hyperdynamic circulation of clinical sepsis $[1,18]$. The purpose of this study was to measure hemodynamic changes including anatomic peripheral A-V shunting after canine cecal ligation, in order to determine the implication of these findings to human sepsis.

\section{METHODS}

Twelve mongrel dogs were judged to be clinically healthy by observation and exclusion of Dirofilaria immitis and stool parasiles. Experiments were performed according to the protocol in Fig. 1 using sodium pentobarbital anesthesia $(25 \mathrm{mg} / \mathrm{kg}$, with small supplementary doses). After "baseline" measurements were obtained (see below), a sterile midline laparotomy was performed and the cecum was devascularized and ligated $10 \mathrm{~cm}$ from its distal end. The abdomen was closed and 250,000 units penicillin $\mathrm{G}$ was administered on Day 0 and Day 1 to prevent overgrowth of anaerobic bacteria. Animals were recovered from anesthesia and allowed free access to food and water. An intravenous infusion of Ringer's lactate $(20 \mathrm{ml} / \mathrm{kg})$ was administered on Day 1 ( $24 \mathrm{hr}$ after cecal ligation) to prevent dehydration. Pilot studies in our laboratory had shown that such cecal ligation resulted in uniform death by 4 to 5 days, but that most animals survived $48 \mathrm{hr}$. Therefore, dogs were restudied $48 \mathrm{hr}$ after cecal ligation (Day 2 : "sepsis"). Following these measurements, intravenous Ringer's lactate $(20 \mathrm{ml} / \mathrm{kg})$ was administered and hemodynamic measurements were repeated ("resuscitation"). Four of the original animals died of overwhelming sepsis prior to Day 2, leaving eight dogs in the final experimental group. Autopsies were performed at the completion of the experiment.

The following hemodynamic measurements were done on Day 0 and Day 2 during baseline, sepsis, and resuscitation. Cardiac output was measured by thermal dilution using a transjugular Swan-Ganz catheter and an Instrumentation Laboratory Model 601 cardiac output computer. Cardiac index (CI) was calculated by estimating body surface area [10]. Pulmonary artery wedge (PAw) and central venous pressures (CVP) were recorded continuously via the SwanGanz catheter. Mean arterial pressure (MAP) was measured via a brachial artery catheter and Statham pressure transducer. Femoral artery flow was measured with a Carolina Model 501 electromagnetic flowmeter and appropriately sized flow probes were placed on the artery by direct cutdown. A small muscular branch of the femoral artery and vein distal to the profunda femoris but proximal to the saphenous branch was cannulated with PE 50 polyethylene tubing for blood pressure recording, blood gas determination, and femoral microsphere injection (see below). Temperature was recorded using the Swan-Ganz thermal dilution catheter. Each animal's initial body temperature was maintained with a heating mattress and overhead heat lamp. Femoral arterial and venous $\mathrm{pH}, p \mathrm{O}_{2}$, and $p \mathrm{CO}_{2}$ were measured with a Dow-Corning Model 175 blood gas 
analyzer. Oxygen $\left(\mathrm{O}_{2}\right)$ saturation was determined from the dog $\mathrm{O}_{2}$-hemoglobin $(\mathrm{Hb})$ dissociation curve and $\mathrm{O}_{2}$ content $\left(\mathrm{ml} \mathrm{O}_{2} /\right.$ $100 \mathrm{ml}$ ) was then calculated as

$\mathrm{O}_{2}$ content $=1.34 \times \mathrm{Hb}$ concentration

$\times$ Hb saturation $/ 100+0.003 \times p \mathrm{O}_{2}$.

Blood cultures were drawn by aseptic technique from a peripheral vein during each sepsis study. Total peripheral resistance (TPR) was calculated as

TPR (dyne $\cdot \mathrm{sec} / \mathrm{cm}^{5}$ )

$=$ MAP-CVP $(\mathrm{mm} \mathrm{Hg}) / \mathrm{CO}$

(liters $/ \mathrm{min}) \times 80$.

Pressure, flow, and temperature were continuously recorded with a Hewlitt-Packard Series 8800 recorder.

Tissue capillary blood flow was determined by microsphere uptake. Carbonized microspheres, $15 \mu \mathrm{m}$ in diameter $(600,000$ in $20 \%$ Dextran, $3 \mathrm{M} \mathrm{Co}$.), were injected over $5 \mathrm{sec}$ via a transcarotid, left ventricular catheter. Different radioactive labeled microspheres $\left({ }^{85} \mathrm{Sr},{ }^{51} \mathrm{Cr}\right.$ or $\left.{ }^{141} \mathrm{Ce}\right)$ were injected at baseline, sepsis, and resuscitation. To calculate tissue blood flow, a femoral artery reference sample was withdrawn at a rate of $15 \mathrm{ml} / \mathrm{min}$ for $1.5 \mathrm{~min}$. Previous results in this laboratory using a dual reference sample technique demonstrated the adequacy of mixing after left ventricular injection for peripheral circulation studies $[6,7]$. In this experiment, equality of right and left kidney counts within 5\% was used as an index of adequate microsphere mixing, which occurred in each animal studied. After the animals were sacrificed, both kidneys, a portion of a right hepatic lobe, the pancreas, lower leg skin, and anterior tibial muscle were removed for microsphere counting. Tissue samples were counted with a 2 -in. $\mathrm{NaI}$ scintillation crystal using a revolving specimen container to eliminate geometric distortion. A Tracor Northern Model 1710 multichannel analyzer was used to discrim- inate the energy spectra of the three isotopes used in this study. Efficient counting with low-background rates reduced overall counting error to less than $7 \%$. Following these measurements each kidney was sectioned sagittally and representative rectangular pieces of cortex were removed and divided into four equal layers (Zone 1, outer, to Zone 4 , inner) as previously described, for determination of intrarenal distribution of blood flow [6]. Renal cortical tissue was counted in a Beckman 8000 gamma spectrometer. The energy spectra of the three isotopes used wcrc differentiated by a multiple linear equation technique. All tissue samples were weighed and blood flow per $100 \mathrm{~g}$ tissue was determined as previously described $[6,7]$. Samples were not analyzed if calculations revealed that fewer than 300 microspheres were found per specimen. This occurred in two dogs, but only with muscle and skin samples.

To measure femoral A-V shunting, human albumin microspheres labeled with ${ }^{99 \mathrm{~m}} \mathrm{Tc}$ ( $\bar{x}=23 \mu \mathrm{m}$, range: $15-35 \mu \mathrm{m}$ in diameter, 40,000 per injection) were sonicated and injected retrograde into the femoral artery. Microspheres passing through A-V shunts larger than this sphere diameter pass to the venous circulation and were trapped in pulmonary capillaries where they were counted using a $\mathrm{NaI}$ scintillation detector and a Tracor Northern Model 1710 multichannel analyzer. At the completion of each study a venous injection was done to represent $100 \%$ shunting. A-V shunting during each arterial injection was calculated by the ratio of pulmonary activity after each arterial injection compared to the venous injection, as previously described $[4,5]$. The contralateral leg from that cannulated on Day 0 (baseline) was used on Day 2, to eliminate local changes secondary to previous operative exposure of the artery.

Using each animal as its own control, results were compared sequentially between baseline-sepsis and sepsis-resuscitation using Student's paired $t$ test to determine statistical significance. 
TABLE 1

Effect of Cecal Ligation Sepsis upon Systemic Parameters

\begin{tabular}{|c|c|c|c|}
\hline & Baseline & Sepsis & Resuscitation \\
\hline $\begin{array}{l}\text { Cardiac index } \\
\quad\left(\text { liters } / \text { min- }-m^{2}\right)\end{array}$ & $3.9 \pm 0.2$ & $3.3 \pm 0.3$ & $4.5 \pm 0.4^{* *}$ \\
\hline $\begin{array}{l}\text { Heart rate } \\
\quad(\text { beats } / \mathrm{min})\end{array}$ & $159 \pm 12$ & $171 \pm 10$ & $170 \pm 8$ \\
\hline $\begin{array}{l}\text { Mean arterial pressure } \\
\quad(\mathrm{mm} \mathrm{Hg})\end{array}$ & $138 \pm 8$ & $116 \pm 6^{*}$ & $114 \pm 8$ \\
\hline $\begin{array}{l}\left(\mathrm{cm} \mathrm{H}_{2} \mathrm{O}\right) \\
\text { Central venous pressure }\end{array}$ & $4.1 \pm 0.7$ & $3.9 \pm 0.6$ & $5.4 \pm 0.8^{*}$ \\
\hline$\left(\mathrm{cm} \mathrm{H} \mathrm{H}_{2} \mathrm{O}\right)$ & $0.2 \pm 0.9$ & $1.6 \pm 0.6$ & $2.3 \pm 0.6$ \\
\hline $\begin{array}{l}\text { Total peripheral resistance } \\
\left(\text { dyn-sec } / \mathrm{cm}^{5}\right) \\
\text { Core temperature }\end{array}$ & $3147 \pm 244$ & $3282 \pm 347$ & $2219 \pm 272^{* *}$ \\
\hline$\left({ }^{\circ} \mathrm{C}\right)$ & $38.5 \pm 0.1$ & $39.6 \pm 0.2^{* *}$ & $39.4 \pm 0.2$ \\
\hline $\begin{array}{l}\text { White blood cell count } \\
\left(\text { cells } \times 10^{3} / \mathrm{mm}^{3}\right)\end{array}$ & $9.6 \pm 1.2$ & $23.4 \pm 4.5^{*}$ & - \\
\hline (vol\%) & $37.1 \pm 1.6$ & $39.8 \pm 1.5^{*}$ & $39.3 \pm 2.0$ \\
\hline
\end{tabular}

Note. Mean \pm SEM. $n=8$.

$* P<0.05$.

** $P<0.01$.

RESULTS

\section{Sepsis}

Despite free access to water and Ringer's lactate intravenous infusion of $20 \%$ estimated blood volume (EBV) on Day 1 (24 hr after cecal ligation), dehydration was manifested on Day 2 during sepsis by hemoconcentration ( $\bar{x}=\uparrow 2.7$ vol\% hematocrit) (Table 1). This appeared to result from intraabdominal fluid sequestration. Autopsies revealed fulminant peritonitis with considerable purulent peritoneal fluid collection. The cecum was edematous, inflamed, and showed necrotic changes. Perforation was evident in several cases, although this did not correlate with early death.

Systemic sepsis was manifested by significant leukocytosis and pyrexia (Table 1). Blood cultures were positive in every animal with a mixture of gram-negative bacteria predominating (Enterobacter, Klebsiella, Escherichia coli), accompanied less frequently by gram-positive organisms (Staphylococcus, Streptococcus). Although abso- lute hypotension did not result, a significant decrease in MAP (from 138 to $116 \mathrm{~mm} \mathrm{Hg}$, $P<0.05)$ occurred after cecal ligation.

Cardiac index decreased in four dogs, increased in two dogs, and was unchanged in two dogs after cecal ligation (Fig. 2), resulting in no significant overall change (Table 1). Neither TPR, PAw, nor CVP significantly changed with sepsis. Although a trend toward tachycardia was observed, this was not statistically significant (Table 1).

Femoral artery blood flow decreased in every dog after cecal ligation, including those two animals with an elevated CI (Fig. 2) (125 to $84 \mathrm{ml} / \mathrm{min}, P<0.01$ ). This $33 \%$ decrease in femoral artery blood flow was associated with a significant $(35 \%)$ increase in femoral vascular resistance (Table 2). Cecal ligation caused a significant increase in $\mathrm{A}-\mathrm{V} \mathrm{O} \mathrm{O}_{2}$ difference $\left(2.4\right.$ to $4.1 \mathrm{ml} \mathrm{O}_{2} / 100$ $\mathrm{ml}, P<0.05$ ), due to increased $\mathrm{O}_{2}$ extraction (reduced venous $\mathrm{O}_{2}$ saturation) (Table 2). Total hindlimb $\mathrm{O}_{2}$ consumption did not change significantly during this study. Anatomic $\mathrm{A}-\mathrm{V}$ shunting in the hindlimb also did not change after cecal ligation (Table 2). 

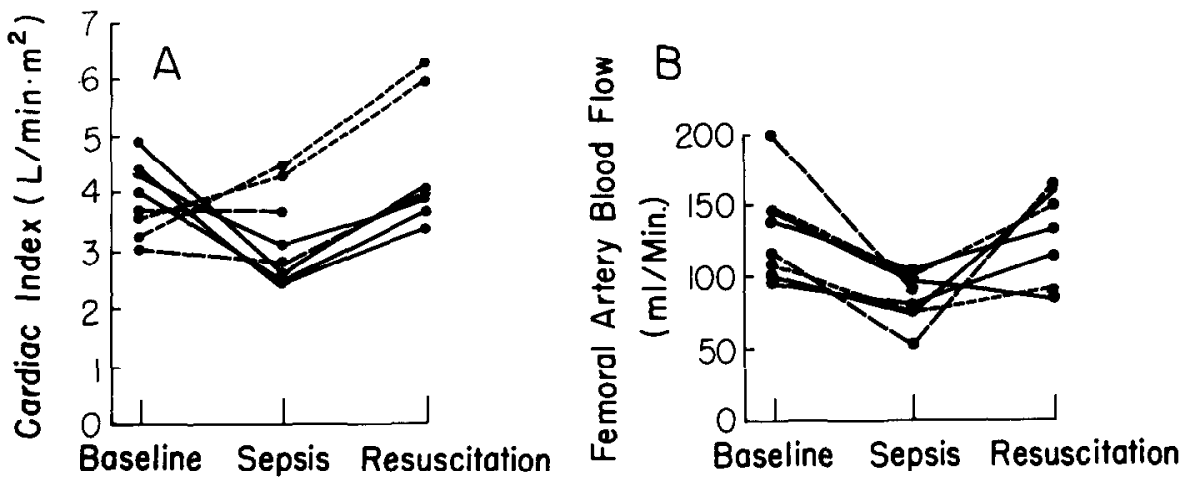

CAROIAC INDEX:unchanged , increased , decreased

FIG. 2. (A) Individual animal changes in $\mathrm{CI}$ with sepsis and resuscitation. (B) Corresponding changes in femoral artery blood flow with sepsis and resuscitation. Note the uniform decrease in femoral artery flow during sepsis even in those four dogs with increased or constant $\mathrm{CI}$.

Tissue microsphere uptake demonstrated significantly increased renal and hepatic blood flow after cecal ligation (Table 3 ). The distribution of cardiac output increased to the kidneys by $63 \%(P<0.01)$ and to the liver, by $168 \%(P<0.01)$. Total renal blood flow (based upon total organ microsphere uptake) increased from $310 \mathrm{ml} / \mathrm{min}$ to 396 $\mathrm{ml} / \mathrm{min}(P<0.05)$, representing an increase from 15 to $24 \%$ of cardiac output. While changes in pancreatic, muscle, and skin blood flow did not reach statistical signifi- cance, this was probably due to the small number of animals and the necessity of discarding several samples due to low microsphere contents. There appeared to be a trend toward decreased pancreatic and muscle blood flow, but increased skin blood flow after cecal ligation.

Intrarenal distribution of blood flow did not vary significantly from baseline during cecal ligation sepsis (Table 4). Increased renal blood flow appeared equally distributed to cortical and juxtamedullary layers.

TABLE 2

Effect of Cecal Ligation Sepsis upon Peripheral Hindlimb Parameters

\begin{tabular}{|c|c|c|c|}
\hline & Baseline & Sepsis & Resuscitation \\
\hline $\begin{array}{l}\text { Femoral artery flow } \\
(\mathrm{ml} / \mathrm{min})\end{array}$ & $130 \pm 12$ & $84 \pm 6^{* *}$ & $128 \pm 12^{*}$ \\
\hline $\begin{array}{l}\text { Femoral vascular resistance } \\
(\mathrm{mm} \mathrm{Hg} / \mathrm{ml}-\mathrm{min})\end{array}$ & $1.09 \pm 0.06$ & $1.47 \pm 0.18^{*}$ & $0.96 \pm 0.14^{*}$ \\
\hline $\begin{array}{l}\text { Femoral artery } \mathrm{O}_{2} \text { saturation } \\
(\%)\end{array}$ & $96 \pm 1$ & $95 \pm 1$ & $96 \pm 1$ \\
\hline $\begin{array}{l}\text { Femoral vein } \mathrm{O}_{2} \text { saturation } \\
(\%)\end{array}$ & $85 \pm 2$ & $76 \pm 3^{*}$ & $87 \pm 2^{*}$ \\
\hline $\begin{array}{l}\text { A-V } \mathrm{O}_{2} \text { difference } \\
\left(\mathrm{ml} \mathrm{O} \mathrm{O}_{2} / 100 \mathrm{ml}\right)\end{array}$ & $2.4 \pm 0.5$ & $4.1 \pm 0.7^{*}$ & $1.9 \pm 0.3^{*}$ \\
\hline $\begin{array}{l}\text { Femoral } \mathrm{O}_{2} \text { consumption } \\
\left(\mathrm{ml} \mathrm{O} \mathrm{O}_{2} / \mathrm{min}\right)\end{array}$ & $3.4 \pm 1.0$ & $3.6 \pm 0.8$ & $2.7 \pm 0.6$ \\
\hline $\begin{array}{l}\text { Femoral A-V shunting } \\
(\%)\end{array}$ & $4.5 \pm 0.7$ & $3.4 \pm 0.9$ & $2.8 \pm 0.6$ \\
\hline
\end{tabular}

Note. Mean \pm SEM. $n=8$.

$* P<0.05$.

$* * P<0.01$. 
TABLE 3

Effect of Cecal Ligation Sepsis upon Selected TISSUE BLOOD Flow

\begin{tabular}{lccr}
\hline $\begin{array}{c}\text { Blood flow } \\
(\mathrm{ml} / 100 \mathrm{~g} \text {-min })\end{array}$ & Baseline & Sepsis & Resuscitation \\
\hline Kidney & $490 \pm 48$ & $674 \pm 93^{*}$ & $607 \pm 37$ \\
Liver & $32 \pm 6$ & $71 \pm 13^{* *}$ & $93 \pm 32$ \\
Pancreas & $120 \pm 46$ & $82 \pm 20$ & $122 \pm 23$ \\
Leg muscle & $35 \pm 14$ & $18 \pm 9$ & $44 \pm 32$ \\
Leg skin & $11 \pm 5$ & $23 \pm 13$ & $26 \pm 9$ \\
\hline
\end{tabular}

Note. Mean \pm SEM. $n=8$.

$* P<0.05$.

$* * P<0.01$

\section{Resuscitation}

After the above determinations, a bolus of Ringer's lactate was infused, which represented $20 \%$ EBV. This infusion immediately increased $\mathrm{CI}$ in all animals $(\bar{x}=3.3$ to 4.6 liters $\left./ \mathrm{min}-\mathrm{m}^{2}, P<0.01\right)$ to a value higher than baseline (Fig. 2). A small, but significant increase in PAw (Table 1) and a $32 \%$ reduction in TPR (3040 to 2160 dyn-sec/ $\mathrm{cm}^{5}, P<0.01$ ) also occurred with this infusion. Heart rate and MAP, however, did not change.

Femoral artery flow significantly increased and femoral vascular resistance decreased after resuscitation, both being restored to their baseline level (Fig. 2) (Table 2). Hindlimb $\mathrm{O}_{2}$ consumption remained statistically constant, due to a significant reduction in $\mathrm{A}-\mathrm{V} \mathrm{O}_{2}$ difference, reflected by a return of femoral venous $\mathrm{O}_{2}$ saturation to baseline (Table 2). Anatomic hindlimb A-V shunting remained unchanged, even in those dogs with significantly increased $\mathrm{CI}$ and femoral artery flow (Fig. 2). Renal and hepatic blood flow remained elevated after resuscitation. Pancreatic and muscle blood flow appeared to return to baseline level, although these values did not reach statistical significance (Table 3). Skin blood flow remained elevated, while intrarenal distribution of blood flow did not change (Table 4).

\section{DISCUSSION}

Cecal ligation in this study produced virulent peritonitis which, despite an elevated cardiac output in two of eight animals, was uniformly associated with increased hindlimb vascular resistance and reduced femoral artery blood flow (Fig. 2). During this sepsis, femoral $\mathrm{A}-\mathrm{V} \mathrm{O}_{2}$ difference increased and peripheral anatomic A-V shunting was minimal and unchanged from baseline. Since it was hoped that this cecal ligation model would reproduce the hyperdynamic, low resistance, peripheral circulation often found in human sepsis, this result was disappointing. The contribution of anatomic A-V shunting to reduced $\mathrm{A}-\mathrm{V} \mathrm{O}_{2}$ difference and decreased peripheral resistance could not be assessed in a model which did not produce these changes in the peripheral circulation. Other investigators, however, using canine cecal ligation, have concluded that $\mathrm{A}-\mathrm{V}$ shunting does not contribute to reduced peripheral vascular resistance in septic shock $[1,18]$.

Archie used 9- $\mu \mathrm{m}$-diameter microspheres to measure A-V shunting 5 days after cecal ligation in dogs [1]. He found increased "shunting" only in the splanchnic circulation of these animals. These dogs, however, demonstrated reduced $\mathrm{CI}$ with increased TPR and increased $\mathrm{A}-\mathrm{V} \mathrm{O} \mathrm{O}_{2}$ difference, analogous to the results of our study. Since capillaries may dilate to $10 \mu \mathrm{m}$ in diameter [13], the use of $9-\mu \mathrm{m}$-diameter microspheres to measure shunting may actually measure capillary vasodilation. This could explain the abnormally high (20\%) baseline hindlimb shunting observed by Archie in control an-

TABLE 4

EfFect of Cecal Ligation Sepsis upon intraRENAL DISTRIBUTION OF BLOOD FLOW

\begin{tabular}{lccc}
\hline $\begin{array}{c}\text { Relative } \\
\text { percentage } \\
\text { distribution }\end{array}$ & Baseline & Sepsis & Resuscitation \\
\hline Zone 1 & & & \\
(outer) & $38.6 \pm 1.8$ & $38.3 \pm 2.8$ & $37.7 \pm 3.3$ \\
$\begin{array}{c}\text { Zone 2 } \\
\text { Zone 3 } \\
\text { Zone } 4 \\
\text { (inner) }\end{array}$ & $30.4 \pm 1.7$ & $30.0 \pm 1.4$ & $29.7 \pm 2.3$ \\
\hline
\end{tabular}

Note. Mean \pm SEM. $n=8$. No significant changes. 
imals [1]. Similarly, the decreased hindlimb shunting observed by Archie during cecal ligation sepsis may represent decreased capillary blood flow, as observed in our study.

Wright et al. studied cecal ligation sepsis in dogs and noted high and low cardiac output response groups [18], as previously observed by others [11]. They found increased hindlimb muscle blood flow measured by Xenon clearance in those dogs with increased cardiac output [18]. This increased muscle blood flow correlated with increased cardiac output, although femoral artery blood fluw was not measured. Similar findings using Xenon muscle blood flow in human sepsis have been reported [9]. Although these authors concluded that significant A$V$ shunting was unlikely, it should be noted that no statistically significant decrease in femoral A- $\mathrm{V} \mathrm{O}_{2}$ difference occurred in their animal model, suggesting, as in our study, that a true hyperdynamic peripheral circulation did not exist.

In both the above-cited animal studies, as in our study, cecal ligation did not produce hyperdynamic peripheral blood flow accompanied by reduced $\mathrm{A}-\mathrm{V} \mathrm{O}_{2}$ difference, the human sepsis counterpart which these models attempt to simulate. The explanation for this depressed peripheral circulation after cecal ligation appears to be marked peritonitis and fluid sequestration, combined with increased renal, hepatic, and splanchnic blood flow. Thal et al. previously reported the association between fluid sequestration in septic canine hindlimbs and a hypodynamic response to sepsis [17]. Nxumalo et al. have shown increased hepatic blood flow (both portal vein and hepatic artery) in dogs responding to cecal ligation with increased cardiac output using indocyanine green measurements [14]. In our animals, increased total hepatic and renal blood flow were universal observations regardless of change in cardiac output.

The effect of peritoneal fluid sequestration upon peripheral hemodynamics is supported by the reversal of these changes with Ringer's lactate resuscitation. Despite resuscitation, however, increased femoral artery flow and decreased A-V O $\mathrm{O}_{2}$ difference (compared to baseline), did not occur. Nor did anatomic, peripheral $A-V$ shunting increase. In contrast to the canine septic hindlimb model, there does not appear to be a specific vasodilator released after cecal ligation which effects peripheral blood flow or A-V shunting. However, since canine cecal ligation does not duplicate the peripheral circulatory changes of hyperdynamic human sepsis, the significance of this observation is unclear.

Despite increased renal blood flow observed in this model, the distribution of intrarenal blood flow was unchanged. This is at variance with previous results from our laboratory which employed live bacterial infusion in awake animals [6]. Previous pilot studies in our laboratory demonstrated that total renal blood flow and intrarenal distribution of flow in dogs were significantly influenced by pentobarbital anesthesia. The depressed effect of pentobarbital on overall septic circulation has also been noted by Hinshaw et al. [11]. In our current cecal ligation study, baseline intrarenal blood flow was distributed more to outer cortical zones than to the juxtamedullary zone than was true in our previous awake studies $[6,7]$. Dehydration alone has been reported to cause such a redistribution [12]. However, this finding did not reverse with Ringer's lactate infusion in our study. Although anesthetic differences may have influenced this blood flow distribution, other investigators have observed unchanged distribution of renal blood flow with sepsis $[2,16]$. Since differing septic models and anesthesia have been employed in these studies, the question of significant shifts in intrarenal blood flow with sepsis, perhaps responsible for clinically observed polyuria, requires further investigation.

The present study has demonstrated that cecal ligation sepsis in dogs produces variable responses in cardiac output, uniformly increased hepatic and renal blood flow, but uniformly depressed peripheral (hindlimb) circulation. This reduced femoral blood flow 
is associated with an increased femoral A-V $\mathrm{O}_{2}$ difference and low A-V shunting. While we have previously demonstrated that significant increases in anatomic A-V shunting contribute to increased femoral blood flow and reduced $\mathrm{A}-\mathrm{V} \mathrm{O}_{2}$ difference in canine septic hindlimbs, these results may only reflect the contribution of local inflammation. The lack of increased $\mathrm{A}-\mathrm{V}$ shunting after resuscitation in this study, plus the persuasive discussion by Siegel $e t$ al. that changes in peripheral blood flow and oxygen utilization during sepsis merely reflect altered intermediary metabolism [15], certainly argue against the clinical significance of anatomic A-V shunting during sepsis. However, a depressed peripheral circulation resulting from peritoneal fluid sequestration and increased splanchnic blood flow makes cecal ligation an inappropriate model upon which to base this conclusion. Such a conclusion awaits the application of direct AVA measurement techniques to human septic shock or to appropriate animal models with hyperdynamic peripheral circulation without the effects of local inflammation.

\section{REFERENCES}

1. Archie, J. P. Anatomic arterial-venous shunting in endotoxic and septic shock dogs. Ann. Surg. 186: $171,1977$.

2. Auguste, L. J., Stone, A. M., and Wise, L. The effects of Escherichia coli bacteremia on in vitro perfused kidneys. Ann. Surg. 192: 65, 1980.

3. Border, J. R., Gallo, E., and Schenk, W. G. Systemic arteriovenous shunts in paticnts under severe stress: A common cause of high output cardiac failure. Surgery 60: 225, 1966.

4. Cronenwett, J. L., and Lindenauer, S. M. Direct measurement of arteriovenous anastomotic blood flow in the septic canine hindlimb. Surgery 85: 275, 1975.
5. Cronenwett, J. L., and Lindenauer, S. M. Direct measurement of arteriovenous anatomic blood flow after lumbar sympathectomy. Surgery 82: 82, 1977.

6. Cronenwett, J. L., and Lindenauer, S. M. Distribution of intrarenal blood flow during bacterial sepsis. J. Surg. Res. 24: 132, 1978.

7. Cronenwett, J. L., and Lindenauer, S. M. The effect of bacterial pyrogen on the distribution of intrarenal blood flow. J. Surg. Res. 26: 285, 1979.

8. Cohn, J. D., Greenspan, M., Goldstein, C. R., Gudwin, A. L., Siegel, J. H., and Delguercio, L. R. M. Arteriovenous shunting in high cardiac output shock syndromes. Surg. Gynecol. Obstet. 127: 282, 1968.

9. Finley, R. J., Duff, J. H., Holliday, R. L., Jones, D., and Marchuk, J. B. Capillary muscle blood flow in human sepsis. Surgery 78: 87, 1975.

10. Hermreck, A. S., and Thal, A. P. Mechanisms for the high circulatory requirements in sepsis and septic shock. Ann. Surg. 170: 677, 1969.

11. Hinshaw, L. B., Solomon, L. A., Holmes, D. D., and Greenfield, L. J. Comparison of canine responses to escherichia coli organisms and endotoxin. Surg. Gynecol. Obstet. 12: 981, 1968.

12. Kirkebo, A., and Tyssebotn, I. Effect of dehydration on renal blood flow in dog. Acta Physiol. Scand. 101: $257,1977$.

13. Nelms, J. D. Functional anatomy of skin related to temperature regulation. Fed. Proc. 22: 933, 1963.

14. Nxumalo, J. L., Teranaka, M., and Schenk, W. G. Hepatic hlood flow measurement. III. Total hepatic blood flow measured by ICG clearance and electromagnetic flowmeters in a canine septic shock model. Ann. Surg. 187: 299, 1978.

15. Siegel, J. H., Cerra, F. B., Coleman, B., Giovannini, I., Shetye, M., Border, J. R., McMenamy, R. H. Physiological and metabolic correlations in human sepsis. Surgery 86: 163, 1979.

16. Stone, A. M., Stein, T., Laforturne, J., and Wise, L. Changes in intrarenal blood flow during sepsis. Surg. Gynecol. Obstet. 148: 731, 1979.

17. Thal, A. P., Robinson, R.G., Nagamine, T., Pruett, R., and Wegst, A. V. The critical relationship of intravascular blood volume and vascular capacitance in sepsis. Surg. Gynecol. Obstet. 143: 17, 1976.

18. Wright, C. J., Duff, J. H., McLean, P. H., Maclean, D. Capillary blood flow and oxygen uptake in severe sepsis. Surg Gynecol. Obstet. 132: 636, 1971. 